\title{
O papel das drogas na vida da criança em situação de rua*
}

\section{The influence of the drugs in the life of the street children}

\author{
Moneda Oliveira Ribeiro(1), Márcia Aparecida Ferreira de Oliveira ${ }^{(2)}$, \\ Ana Luisa Aranha e Silva ${ }^{(3)}$, Sônia Barros ${ }^{(4)}$
}

RIBEIRO, M. O.; OLIVEIRA, M. A. F. de, SILVA, A. L. A. e, BARROS, S. O papel das drogas na vida da criança em situação de rua. Rev. Ter. Ocup. Univ. São Paulo, v. 14, n. 2, p. 79-84, maio/ago. 2003.

RESUMO: O texto aborda parte dos dados de um estudo referente à trajetória de vida de um grupo de crianças de rua, em idade escolar, que freqüentavam dois refúgios da cidade de São Paulo. Os dados, coletados em entrevistas individuais, foram gravados, transcritos e analisados segundo método de Análise de Conteúdo e princípios da teoria da Representação Social. As categorias temáticas destacadas do discurso transcrito foram agrupadas em experiências significativas para as crianças, entre as quais "as drogas". A síntese das categorias analisadas evidenciou que a violência permeia a vida dessas crianças, resultando em experiências que interferem em momentos críticos do desenvolvimento delas. As drogas constituem um dos agentes sociais agressores, sendo utilizadas como meio de inserção da criança nos grupos de pares que vivem na rua.

DESCRITORES: Menores de rua. Transtornos relacionados ao uso de substâncias psicoativas. Saúde escolar. Alienação social. Criança institucionalizada. Violência. Adolescente institucionalizado.

* Parte da Tese de Doutorado titulada "A criança de/na rua: um olhar sobre sua trajetória de vida", apresentada à Escola de Enfermagem da USP, em 10/12/99.

(1) Enfermeira. Professora Doutora do Departamento de Enfermagem Materno-Infantil e Psiquiátrica da Escola de Enfermagem da Universidade de São Paulo. E-mail: moneda@usp.br

(2) Enfermeira. Professora Doutora do Departamento de Enfermagem Materno-Infantil e Psiquiátrica da Escola de Enfermagem da Universidade de São Paulo. E-mail: marciaap@usp.br

(3) Enfermeira. Professora Doutora do Departamento de Enfermagem Materno-Infantil e Psiquiátrica da Escola de Enfermagem da Universidade de São Paulo. E-mail: anaranha@usp.br

(4) Enfermeira. Professora Doutora do Departamento de Enfermagem Materno-Infantil e Psiquiátrica da Escola de Enfermagem da Universidade de São Paulo. E-mail: sobarros@usp.br

Endereço para correspondência: Moneda Oliveira Ribeiro - Av. Dr. Enéas de Carvalho Aguiar, 419. Cerqueira César - São

Paulo, Brasil - CEP 05403-000. e-mail: moneda@usp.br 


\section{INTRODUÇÃO}

$\mathrm{N}$ o Estatuto da Criança e do Adolescente - ECA (Lei No 8.069, de 13/07/90) que regulamenta o artigo 227 da Constituição brasileira de 5 de outubro de 1988 está expresso: "É dever da família, da sociedade e do Estado assegurar à criança e ao adolescente, com absoluta prioridade, o direito à vida, à saúde, à alimentação, à educação, ao lazer, à profissionalização, à cultura, à dignidade, ao respeito, à liberdade e à convivência familiar e comunitária, além de colocá-los a salvo de toda forma de negligência, discriminação, exploração, violência crueldade e opressão" (DIREITOS, 1993).

Assim sendo, cabe a todo cidadão, enquanto indivíduo ou membro representativo dos distintos setores da sociedade, contribuir para assegurar direitos às crianças brasileiras. Para tanto, é preciso fazer o diagnóstico real da situação da criança no Brasil. Encarar com realismo os dados estatísticos que configuram a situação de exclusão de diversas crianças e famílias do acesso aos bens sociais. Promover a saúde das famílias brasileiras envolve medidas difíceis de serem implementadas porque implica questões de ordem política. Por isso, para resgatar a criança e o adolescente da situação de rua, é necessário envolver toda a sociedade civil. O engajamento nas organizações sociais (governamentais ou não, partidárias ou não) em prol da criança excluída poderá influenciar a mudança dessa realidade.

As formas de engajamento políticoorganizacional podem se dar de distintas formas, seja na investigação científica, no trabalho educacional, nas manifestações populares, nas atividades desenvolvidas pelas ONGs, nos Conselhos Tutelares, nas doações financeiras às entidades de reconhecida idoneidade, etc. Enfim, somente no exercício da cidadania que se encontra mecanismos para, pelo menos de imediato, minimizar o quadro dramático em que se encontram as crianças em situação de rua.

Esse artigo consiste em apresentar um aspecto da realidade de um grupo de crianças de rua em idade escolar, enfocando sua relação com as drogas. Pretende-se assim, ajudar a subsidiar o profissional de saúde em busca de medidas alternativas para promover o desenvolvimento de crianças que se encontram em situação de rua.

\section{METODOLOGIA}

O presente trabalho é parte integrante de uma pesquisa qualitativa sobre a trajetória de vida de um grupo de crianças em situação de rua. Participaram da investigação crianças de 7 a 12 anos que tinham história de vivência nas ruas da cidade de São Paulo. A coleta dos dados consistiu em entrevistas individuais, semiestruturadas, com o intuito de identificar a representação das crianças em relação a sua auto-imagem, a seu grupo familiar, a seu meio comunitário e as demais relações relatadas por elas. Quinze crianças foram convidadas a participarem do estudo, houve uma única recusa. Das catorze entrevistadas, cinco estavam morando em um abrigo (estadia por tempo integral) administrado por uma instituição estadual, e as demais freqüentavam um albergue (estadia noturna) administrado por uma entidade não-governamental. aos responsáveis pelas referidas entidades e às próprias crianças. Teve-se a cautela de esclarecer, em linguagem simples e concreta, o objetivo da pesquisa, o procedimento das entrevistas e o sigiloso de sua identidade. As crianças e seus responsáveis (no caso, o guardião legal) também foram esclarecidos sobre o emprego de suas informações. Depois de sanado suas dúvidas, registraram por escrito o Consentimento Pós-informado, conforme os preceitos éticos da Resolução $n^{\circ}$ 196/96 sobre pesquisa envolvendo seres humanos (BRASIL, 1996).

As entrevistas começavam com uma pergunta inespecífica (por exemplo: "fale sobre sua experiência na rua", ou "o que uma criança sente quando mora na rua") e transcorriam conforme a natureza da criança. Geralmente, as crianças falavam espontaneamente, apenas a algumas era preciso solicitar para esclarecerem colocações confusas ou para discorrerem seu relato com mais detalhe.

As entrevistas foram gravadas e transcritas na íntegra. Desse modo, foi possível registrar com precisão os relatos das crianças e obter a visão delas em relação ao propósito do estudo. Os textos transcritos foram organizados segundo as técnicas de Análise de Conteúdo, descritas por Bardin (1979) e os fundamentos teóricos da Representação Social conforme explica Minayo (1993) e Spink (1993).

Os temas abordados nos textos transcritos referentes às representações das crianças sobre as dificuldades enfrentadas em sua trajetória de vida foram organizados em categorias. Assim, um dos temas que surgiu da análise do discurso das crianças entrevistadas originou a categoria "as drogas".

\section{RESULTADOS}

Todas as crianças, sem exceção, eram dependentes da cola. Cheirar cola parecia ser a condição 
para a inserção das crianças em qualquer grupo. Isso não era explicito, mas elas deixavam transparecer que para pertencerem a um grupo, não poderia diferir-se entre si. O lema é "um por todos e todos por um". Internamente, o grupo precisa estar em conformidade para que seus integrantes permaneçam unidos. Nesse caso, torna-se difícil estabelecer o limite entre solidariedade e cumplicidade. "Quem avisa, amigo é". Esse provérbio é ignorado pelos membros do grupo no tocante às drogas. As crianças são conscientes que a cola "faz mal", entretanto incitam até o melhor amigo a iniciar-se nessa perigosa aventura. A cola proporciona um falso bem-estar temporário e seu consumo torna-se uma rotina, sendo motivo de maus-tratos pela polícia ou de desavenças entre os pares de outros grupos.

\section{AINICIAÇÃO}

Normalmente, é no ciclo de amizades que se inicia a rotina de cheirar cola. Muitas vezes, é o amigo mais próximo que convida a criança a experimentar a droga. Eventualmente, essa iniciativa é da própria criança.

K. Eu comecei a usar cola com meu amigo. (...)

P. Vocêfalou que tem vontade de parar de usar cola. É difícil parar?

K. É.

H. Eu vim com os moleque pra cá. Daí os moleque começou fazer eu usar droga. (...) Daí foi um negócio me tocando pra mim ficar usando todo dia.

A. O primeiro dia que eu fugi, eu não cheirava cola. Aí, quando eu vi um moleque cheirando, eu fui lá e comprei. Aí me deu vontade de cheirar todo dia; aí eu fiquei cheirando, cheirando, cheirando. Depois eu vi na reportagem que a cola faz mal, que um moleque de treze anos foi cheirando cola uma atrás da outra e o pulmão dele ficou bem cheio, só de cola. Aí, nesses tempos eu parei, mas só que eu não consegui parar de cheirar cola.

O consumo da cola leva algumas crianças a iniciar o uso de outras drogas mais pesadas, geralmente o craque e/ou a cocaína, tornando-as muito dependentes desses entorpecentes.

K. Estou tentando parar de fazer coisa ruim, cheirar cola, fumar cigarro, maconha. Tem... uma coisa... a pedra, também, que eu nunca fumei, mas estou com vontade de fumar.

P. Você quer experimentar a pedra?

$K$. É, mas eu não estou com vontade.
P. É perigoso.

K. É. Meu irmão fuma pedra.

P. Você sente falta da cola?

K. Assentiu com a cabeça.

P. Você gostaria que alguém te ajudasse a sair dessa?

K. Gostaria.

\section{ADEPENDÊNCIA}

Uma vez dependentes das drogas, as crianças já não conseguem reintegrar em seu meio familiar: não aceitam restrições, resistem à disciplina e têm dificuldade de retomar seus estudos. Elas passam a viver um conflito permanente, sentem vontade de voltar para casa ou de reconstruir suas vidas em situação mais favorável, sabem que a rua não é saudável para elas, mas não conseguem renunciar à vida na rua por causa da dependência da droga. Vivem assim, um círculo vicioso, um dilema: desejam abandonar a droga, mas não conseguem superá-la, recuam quando alguém as estimulam ao abandono da mesma.

P. Como é sua experiência na rua? Como você se sente?

H. Tia, eu me sinto bem, mas eu estou com saudade de ir pra casa, de visitar minha mãe. Eu queria ir pra casa, mas alguma coisa está em mim pra não ir. Esses dias eu ia visitar minha mãe, mas eu não fui. Eu não consigo, não consigo. Eu volto pra trás. Hoje eu fui pro CCA, tô tentando trabalhar pra ir pra casa, vou tentar ir pra casa, a assistente social vai me encaminhar, acho. Eu quero voltar pra casa, tia. (...) Minha mãe sempre liga pro SOS pra saber se eu tô lá. As tias fala que eu fugi. Eu quero viver outra vida, eu quero viver com a minha mãe, mas...

P. O que levou você a sair de casa?

H. As drogas, tia.

P. Que droga você usa?

H. A cola.

P. Mais alguma?

H. Não.

P. Você não consegue ficar longe da cola?

H. Alguma coisa toca em mim, pra mim usar, não sei, alguma coisa toca em mim. Algo me empurra de volta, pra voltar pra cá, ficar usando droga, fazer o que não é certo, ficar bagunçando, ficar zoando. 
Outro caso:

P. Você tem alguém da sua família com quem poderia ficar?

A. Não.

P. Nem um tio ou uma avó que ficaria com você?

A. Minha avó morreu, meu avô também.

P. Etios?

A. Eles não querem ficar comigo. Já passei pelo Conselho Tutelar, não adiantou. Eu fugi de lá. Fugi por causa da cola, porque eu cheguei lá com a latinha de cola e eles tomaram de mim. Eu peguei a latinha de volta e fugi. (...) Eu não consigo parar de cheirar cola. Sempre, quando eu tô na rua, eu penso em cola, cola, cola. Aí eu vou no farol do Ibirapuera, peço bastante dinheiro e compro a cola, e fico cheirando lá na Praça do Correio. Aí eu encontro meus colega, a gente arruma bastante dinheiro, bastante mesmo, quase dez conto. Aí nós compramos logo uma lata pra nós cheirar. Aí ficamos muito na nóis. Eu ia parar de cheirar cola, mas só que eu não consegui. Fui cheirando, cheirando, cheirando até parar de me dar vontade. Mas eu não consigo ficar sem vontade de cheirar cola, porque quando eu vejo os outros cheirando, eu já vou e peço.

A. O tio (um educador) sempre me dava conselho, só que não adiantava o conselho dele, eu não obedecia. Ele tava me dando conselho bom pra eu não ir nas idéias desses moleques, pra eu não cheirar cola, mas só que eu não consegui parar de cheirar cola.

\section{A SOLUÇÃO}

A solução para as crianças livrarem-se da dependência da cola é, sem dúvida, a desintoxicação. Algumas crianças sabiam que esta era uma alternativa, mas outras não sabiam o que fazer a respeito desconheciam a possibilidade de recuperarem-se desse mal.

P. O que você sente quando fica sem a cola?

H. Minha cabeça fica doendo. Fico com dor de cabeça, dor na garganta. (...) Eu quero ser encaminhado pra uma casa de recuperação, tia. Quero me recuperar. Faz dois tempo que eu fui levar meu amigo pra casa de Campinas, ele ficou lá. Eu quero uma coisa pra mim tomar e nunca mais cheirar cola. Não quero usar mais nada disso.

$P$. Você já tentou falar isso pro médico, ver se ele te ajuda?

H. Aqui tem médica, mas só que elas não atendem

P. É isso que está atrapalhando a sua vida?

H. É, eu vejo a cola e logo peço pros outros, daí eles me bate.

Outro caso:

P. Você chegou a pedir algum tratamento para se livrar da dependência da cola? Você chegou a ir ao hospital?

A. Já, mas só que não adiantava fazer isso, eles não fez nada, só deu um remédio ruim que não deu pra nada.

P. Você conhece alguma casa de recuperação?

A. Não.

P. Se você pudesse, sairia da rua?

A. Mas eu não consigo sair da rua.

\section{DISCUSSÃo}

As drogas são mais um agravante na vida da criança em situação de rua, tornam as relações interpessoais nos grupos, extremamente complexas. As crianças presenciam as reações adversas nos colegas quando estão sob seu efeito. Sabem que perdem o controle sobre si e que, por isso, estão vulneráveis quando as utilizam.

Segundo Whaley e Wong (1989), a inalação da cola plástica (hidro e fluorocarboneto) em sacos plásticos ou de papel, produzem euforia e alteram a consciência. São drogas perigosas porque causam rápida perda da consciência, podendo levar à parada respiratória, sendo que pode não haver tempo suficiente para a retirada do saco plástico da cabeça resultando em asfixia da criança. As autoras referem que, num programa de reabilitação, é necessário identificar não só o problema que motivou a criança a recorrer à droga, como também a função que ela desempenha na sua vida que justifica seu comportamento autodestrutivo.

Tiba (1996) apresenta duas razões principais que justificam o envolvimento de crianças ou jovens com a droga. Baseando-se em sua experiência, conta que "os casos mais complicados de delinquiência ou abuso de drogas recebem uma contribuição enorme da falta de ação do pai. Em última instância, o pai é o grande controlador e a mãe, a grande apoiadora. (...) Não há nenhuma proibição na família, eles fazem tudo o que querem. (...) Com o uso de drogas, é a mesma coisa: o filho não respeita seu próprio limite e vai abusando, abusando, e depois 
perde o controle porque a droga distorce a personalidade. Quando falha o grande controlador, que é a família representada na figura do pai, os abusos começam a acontecer. E, quando um abuso é bemsucedido, ele se estende para o social, na delinqüência, na compulsão pelas drogas".

$\mathrm{O}$ autor pondera sobre outra possibilidade que favorece a aproximação com a droga. Parece conciliar o pensamento de Bowlby (1981, 1990, 1993) e Erikson (1971, 1987) quando estabelece uma relação entre as fases do desenvolvimento infantil e o consumo de drogas. Ele diz que se as etapas do desenvolvimento dos primeiros anos de vida da criança forem frustradas por ausência ou excesso de zelo materno, ela não completa seu ciclo de formação da personalidade. $\mathrm{O}$ autor denomina esse processo incompleto de personalidade aberta e o processo completo chama de personalidade formada. "Tal abertura dificulta ou impede que a criança se considere uma pessoa segura, independente, capaz de fazer as suas coisas e com os seus próprios pensamentos e sentimentos enfrentar sozinha situações novas". Nesse caso, quando a criança atinge a idade escolar, elege uma pessoa com a qual estabelece uma ligação materna. "A criança repete com essa pessoapreenchente a ligação com a mãe, isto é, uma ligação de forte dependência titânica".

Segundo Tiba (1996), na puberdade, o jovem sente necessidade de mostrar que é auto-suficiente. Esse ímpeto pela independência e o sentimento de onipotência obriga ao jovem de personalidade aberta a romper com seus preenchentes, ainda que lhe cause sofrimento. "Se o sofrimento for muito grande e houver a necessidade de preencher a abertura, o púbere pode lançar mão de qualquer preenchente: idéias fanáticas; partidarismos exagerados (religiosos; esportivos; políticos; grupos musicais, sociais, culturais etc.); obsessivas coleções, leituras, e até mesmo drogas”. Este último dá a ilusão de suprir todas as necessidades do indivíduo. "A pessoa pode ter a sensação de estar produzindo através da droga. A personalidade aberta tem dificuldades em acreditar na sua própria capacidade de produção, porque se autodesvaloriza bastante (...). A pessoa pode (também) não mais se sentir carente de afeto, de cuidado e de calor humano, porque julga bastar-se com a droga".

A história de vida das crianças em situação de rua supõe um processo de desenvolvimento frustrado desde pequenas. No momento atual, em que necessitam realizar tarefas valorizadas pelo mundo adulto, estão impossibilitadas de realizá-las, sendo esta uma fase também frustrada. Partindo-se dos pressupostos do referido autor, é esperado que esse processo de aproximação à droga seja mais precoce nessas crianças que estão mais expostas a situações extremamente ameaçadoras, exigindo delas uma capacidade de enfrentamento que, mesmo para a criança com personalidade formada, requer uma habilidade desproporcional a sua fase do desenvolvimento.

\section{CONSIDERAÇÕESFINAIS}

As crianças em situação de rua contam, sobretudo, com os amigos para ajudá-las. Amigos que, por estarem nas mesmas condições e por serem crianças, ajudam muito pouco. Por isso, a solidariedade mútua não basta para suprir suas carências. Elas necessitam dos adultos, tanto do cidadão comum como das autoridades, para viabilizar ações efetivas com meta a solucionar seus problemas (que são tão desproporcionais a sua pouca idade).

Do ponto de vista governamental, a solução dessa problemática social reside em rever as prioridades a que se destina o orçamento público. É necessário aumentar a parcela dos orçamentos nacional e estadual que vem sendo, de modo restrito, destinada à saúde e educação. Mas, somente a manifestação da sociedade civil poderá reverter as prioridades do orçamento público em prol da criança e do adolescente.

Do ponto de vista dos cidadãos, cada um, principalmente os que trabalham nos setores prioritários de atendimento à criança, ou seja, na saúde e na educação, podem contribuir para a solução do problema. Mas as atuações envolvem uma participação que transcende o âmbito da assistência a nível hospitalar ou escolar. É preciso maior engajamento nas diversas possibilidades de atuação a favor da criança em situação de exclusão social.

Nestes termos, cada cidadão tem um compromisso. Todos são co-responsáveis pela superação das condições de vida da criança em situação de rua. Exercer a cidadania não consiste apenas em praticar o direito de voto. O papel social do profissional de saúde compreende o compromisso político com as inúmeras crianças excluídas do sistema de saúde. Tal como refere Soares (1997) “(...) como profissionais da área social e de saúde, possuímos, ou devemos possuir, maior sensibilidade social e proximidade com aqueles que sofrem". 
RIBEIRO, M. O.; OLIVEIRA, M. A. F. de, SILVA, A. L. A. e, BARROS, S. The influence of the drugs in the life of the street children. Rev. Ter. Ocup. Univ. São Paulo, v. 14, n. 2, p. 79-84, maio/ago. 2003.

\begin{abstract}
The paper focuses partial dates of the thesis about the trajectory of a group of school-age children who used to frequent two public São Paulo city shelters. The data, gathered by means of interviews, were analysed according to the theory of the Social Representation and method of the Analysis of Contents. The thematic theories detached from the speech transcript, were grouped into meaningful experiences for the children, among which "the drugs". The synthesis of the analysed categories showed clearly that violence permeates the lives of those children, resulting in experiences that restrict their full development. The thesis points out that the drugs are the away of insertion at the group peers homeless.
\end{abstract}

KEY WORDS: Homeless youth. Substance-related disorders. School health. Social alienation. Child, institucionalized. Violence. Adolescent, institucionalized.

\title{
REFERÊNCIAS
}

BARDIN, L. Análise de conteúdo. Lisboa: Edições 70, 1979.

BOWLBY, J. Cuidados maternos e saúde mental. São Paulo: Martins Fontes, 1981.

BOWLBY, J.Apego. 2.ed. São Paulo: Martins Fontes, 1990. v.1

BOWLBY, J. Separação: angústia e raiva. 2. ed. São Paulo: Martins Fontes, 1993. v.2

BOWLBY, J. Perda: tristeza e depressão. São Paulo: Martins Fontes, 1993. v.3

BRASIL. Ministério da Saúde. Conselho Nacional de Saúde. Resolução $n^{\circ}$ 196/96 sobre pesquisa envolvendo seres humanos. Brasília, 1996.

DIREITOS da criança e do adolescente. São Paulo: Fundo Social de Solidariedade do Estado de São Paulo, 1993.

ERIKSON, E. H. Infância e sociedade. 2.ed. Rio de Janeiro: Zahar, 1971. Cap.7, p.227-53: Oito idades do homem.

ERIKSON, E. H. Identidade, juventude e crise. Rio de
Janeiro: Guanabara, 1987. Cap.3, p.90-141: O ciclo vital epigênese da identidade.

MINAYO, M. C. de S. O desafio do conhecimento: pesquisa qualitativa em saúde. 2.ed. São Paulo, Rio de Janeiro: Hucitec/ Abrasco, 1993

SOARES, L. T. R. Globalização e exclusão: o papel social do enfermeiro. Rev. Enf. Esc. Anna Nery, Rio de Janeiro, v. 1, n. 1, p.13-21, 1997.

SPINK, M. J. (Org.) O conhecimento no cotidiano: as representações sociais na perspectiva da psicologia social. São Paulo: Brasiliense, 1993.

TIBA, I. Disciplina: o limite na medida certa. São Paulo: Gente, 1996.

WHALEY, L. F.; WONG, D. L. Problemas de saúde na idade escolar e na adolescência. In: WHALEY, L. F.; WONG, D. L. Enfermagem pediátrica: elementos essenciais à intervenção efetiva. 2.ed. Rio de Janeiro: Guanabara, 1989. p.358-83. 